and, via 'green urbanism', reconnecting with nature. In contrast to the hard-nosed social psychiatric research that forms its bulk, the final words of this slim, eloquent and indispensable volume are 'plum blossom in spring'. Make that into your next app, Bill.

Jeremy Holmes, School of Psychology, University of Exeter, Exeter EX4 4QG, UK. Email: j.a.holmes@btinternet.com

doi:10.1192/bjp.2018.51

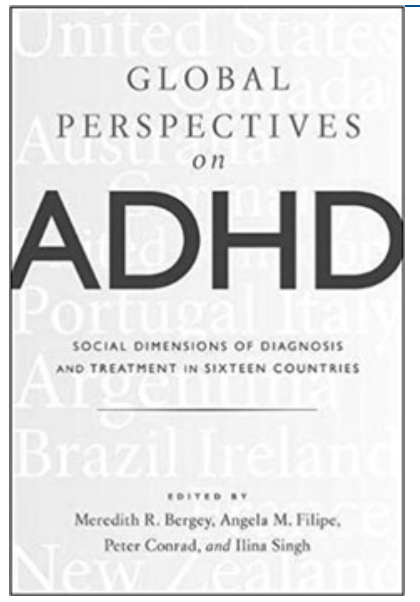

\section{Global Perspectives on ADHD: Social Dimensions of Diagnosis and Treatment in Sixteen Countries}

Edited by Meredith R. Bergey, Angela M. Filipe, Peter Conrad and Ilina Singh.

Johns Hopkins University Press. 2017.

$£ 48.00$ (pb). 416 pp. ISBN 9781421423791

My child psychiatry training from the early to mid-1990s was largely systemically orientated. During my training years, I came across occasional diagnoses of hyperkinetic disorder and even less occasional prescription of stimulant medication. Sadly, some systemic and psychotherapeutic practice in those days was caught up, whether intentionally or not, in parent-blaming (particularly mother-blaming) narratives. In the mid-1990s a mixture of factors contributed to the rise of the 'it is in the child's genes/biology' paradigm as opposed to the 'parents - they $\mathrm{f}^{* *} \mathrm{k}$ you up' story. Understandably, this felt like a positive change for many parents. Pharmaceutical marketing, neoliberal commodification, performance-obsessed institutions (schools, clinics) and therefore performance-anxious parents and/or children, shifting cultural spaces for young people (e.g. the move online), guild anxieties (doctors who do not feel they can be doctors if they are not prescribing), pharmaceutical-supported parent advocacy, media campaigns and so on all played their part in expanding the diagnosis from the narrow, rare diagnosis of hyperkinetic disorder to the nowubiquitous diagnosis of attention-deficit hyperactivity disorder (ADHD). None of the reasons behind this growth related to science because (despite decades of research) no replicable evidence exists to support the idea that ADHD can be viewed as a known/ knowable 'natural category' with unique characteristics that enable it to be differentiated from other natural categories. It is therefore an excellent example of a 'cultural construct'.

Therefore, as you can imagine, I was pleased to be asked to review this book. Written largely by sociologists, I thought this would be an ideal opportunity to scratch below the surface and examine how the concept of ADHD intersects with a variety of local dynamics around childhood, consumerism, globalisation, family and education (to name but a few). The book has chapters relating to practice around $\mathrm{ADHD}$ in sixteen countries: USA, Canada, Australia, Germany, UK, Portugal, Ireland, Argentina, Brazil, Italy, France, Japan, New Zealand, Chile, Taiwan and Ghana. Unfortunately, the book largely fails to deliver. Each chapter is mostly a rehash of previous chapters, illustrating the depressing expansion of the concept of ADHD with little attempt to situate this in the broader context of discourses about childhood, child rearing and economy (for instance). Most chapters have a predictable format and include facts and figures around epidemiology, rates of diagnosis and use of medication or therapy. They look at the role of advocacy groups, the impact this has had on aspects such as educational or social policy, and skim over the contribution of the pharmaceutical industry. Most chapters approach ADHD as a static 'thing' that is being more 'recognised'. Few approach $\mathrm{ADHD}$ as a dynamic cultural construct to start with, which would have led authors to be more open to examining social/cultural and political dimensions of how such a category emerges in relation to existing discourses about childhood, parenting and child development.

Some of the more interesting exceptions included the chapter on Chile, which discusses how the neoliberal economic reforms (Chile was one of the first countries in the world to implement such reforms) led to 'constant and sharp surveillance of children's actions and behaviours', which in turn spurred on the extensive use of methylphenidate in young people. The chapters on Japan and Ghana were also interesting as they revealed how some countries were not caught up in the globalisation of the ADHD epidemic, mainly due to more robustly held cultural attitudes towards parenting and children's development. In Japan this was reflected in the 'official' guidelines for treatment of ADHD, which emphasises psychosocial approaches and has strict criteria around the prescription of pharmaceuticals, including advice about dosing, duration, monitoring, treatment goals, and warnings about addiction and abuse potential. These guidelines are much better in terms of both evidence base and clinical relevance than the current National Institute for Health and Care Excellence guidelines.

Overall, there were a few bright spots in an otherwise disappointing book.

Sami Timimi, Consultant Child and Adolescent Psychiatrist, Lincolnshire Partnership National Health Service Foundation Trust, UK. Email: stimimi@talk21.com

doi:10.1192/bjp.2018.108

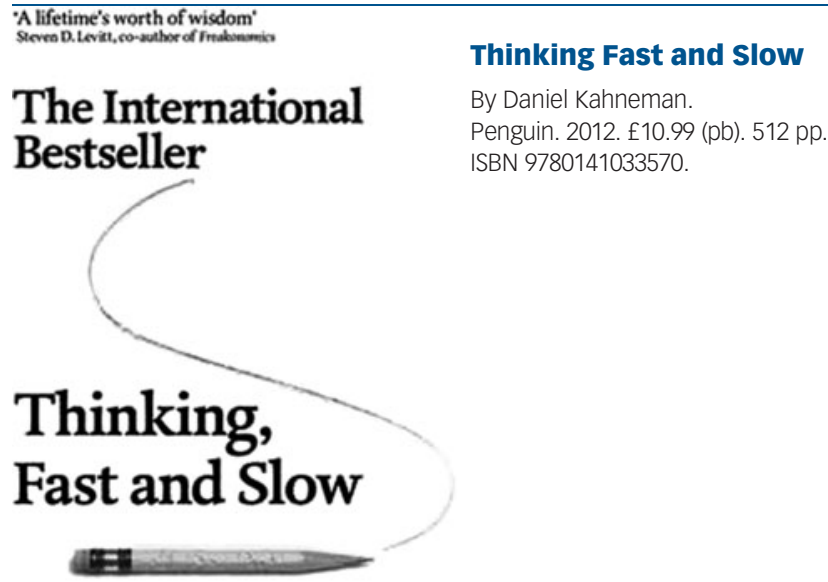

\section{Daniel Kahneman}

Winner of the Nobel Prize

In his book Thinking Fast and Slow, Daniel Kahneman puts the cat among the pigeons as regards human rationality. He purports to 